\title{
Note
}

\section{Suicide seasonality: Evidence of 11-year cyclic oscillations in Brazilian suicide rates}

\section{Sazonalidade do suicídio: Indícios de oscilações cíclicas de 11 anos nas taxas de suicídio brasileiras}

\author{
Walter Sydney Dutra Folly ${ }^{1}$
}

\begin{abstract}
Several researchers have studied suicide seasonality through different statistical approaches. In the present research, we performed a detailed statistical study of Brazilian suicide data registered from 1980 to 2010 using a new approach known as Threshold Bias Model (TBM). Eleven-year cyclic oscillations were observed in suicide rates that, at first sight, appear as being negatively correlated with the cycles of solar activity. Such oscillations are more noticeable for males although they also have been observed in the female rates.
\end{abstract}

Keywords: suicide; seasonal variations; solar activity.

\section{Resumo}

Vários pesquisadores têm estudado a sazonalidade do suicídio utilizando diversas abordagens estatísticas. Na presente pesquisa, realizamos um estudo estatístico dos dados de suicídio brasileiros registrados entre 1980 e 2010 utilizando uma nova abordagem conhecida como Modelo da Tendência Limiar (TBM). Foram observadas oscilações com período de 11 anos nas taxas de suicídio que, à primeira vista, parecem ser negativamente correlacionadas com os ciclos de atividade solar. Essas oscilações foram mais notáveis nas taxas masculinas, ainda que também tenham sido observadas nas taxas femininas.

Palavras-chave: suicídio; variações sazonais; atividade solar.

Study carried out at Universidade Federal de Sergipe (UFS) - Itabaiana (SE), Brasil.

${ }^{1}$ DSc, Adjunct Professor and Researcher at Núcleo Integrado de Pesquisa e Pós-Graduação em Educação e Ciências (NIPPEC), UFSE - Itabaiana (SE), Brasil. Mailing address: Walter Sydney Dutra Folly - Avenida Vereador Olímpio Grande, s/n - CEP: 49500-000 - Itabaiana (SE), Brazil - E-mail: wfolly@ufs.br Financial support: none.

Conflict of interest: nothing to declare. 


\section{INTRODUCTION}

Suicide seasonality is a multifactorial phenomenon that is often associated with the increased winter-summer variation in the number of sunlight hours that occurs in temperate and polar zones of the globe ${ }^{1,2}$. Consequently, its occurrence has been little studied in the tropics.

In Brazil, a previous study conducted between 1996 and 2004 in the city of São Paulo (located on the Tropic of Capricorn) did not revealed significant correlation between suicides and the number of sunlight hours ${ }^{3}$. However, beyond the hypothetical influence of the daily duration of sunlight on suicide rates, several authors have reported that long-term seasonal patterns in such rates may be correlated with solar and geomagnetic activities ${ }^{4-7}$.

Since seasonal oscillations in suicide rates may be small in comparison with data fluctuations due to death undercounting and/or cause of death misclassification, researchers are using several statistical methods in order to quantify this phenomenon ${ }^{8,9}$. Considering this, we performed a preliminary study of suicide seasonality in Brazil employing the recently proposed Threshold Bias Model (TBM) ${ }^{10}$ - a model that provides useful comparison parameters to help us identify seasonality patterns.

\section{METHOD}

The present research considers male and female suicide rates structured by age that were recorded in Brazil from 1980 to 2010. Such data are openly available from the website of DATASUS $^{11}$. In the same way, the average sunspot numbers considered here (relating to solar cycles 21, 22 and 23) can be freely obtained from the website of the Solar Influences Data Analysis Center (SIDC) $)^{12}$.

All analyses were made using the software Microcal Origin version $5.0^{13}$. In this software, suicide rates were edited in proper worksheets and plotted as functions of age. Then, we employed the Levenberg-Marquardt method to fit Equation 1 (TBM distribution) to these datasets considering $\beta=11$ as discussed in Folly ${ }^{10}$. The meanings of all TBM parameters were explained in this reference.

$$
\begin{aligned}
& S R(t)=\left\{\begin{array}{cr}
0 & \text { if }\left(t<t_{c}\right) \\
{\left[a \cdot\left(\frac{\beta+1}{\tau_{1 / 2}}\right) \cdot\left(\frac{t-\tau_{1 / 2}}{\tau_{1 / 2}}\right)^{\beta}+b-V_{0}\right] \cdot C_{a p} .}
\end{array}\right. \\
& \exp \left[-a\left(\frac{t-\tau_{1 / 2}}{\tau_{1 / 2}}\right)^{\beta+1}+V_{0} \cdot\left(t-\tau_{1 / 2}\right)\right] \text { if }\left(t \geq t_{c}\right)
\end{aligned}
$$

After all the distributions were fitted, we used the values of the parameters $b, V_{0}$ and $C_{a p}$ to calculate the middle-age suicide rates $S R\left(\tau_{1 / 2}\right)$ for each year from 1980 to 2010 using the expression $S R\left(\tau_{1 / 2}\right)=\left(b-V_{0}\right) . C_{a p}$. Such distributions were numerically integrated (using Origin's integration tool) from the critical age $t_{c}$ to infinity in order to determine the areas under the curves. The values of $t_{c}$ can be calculated using Equation 2.

$t_{c}=\tau_{1 / 2}-\tau_{1 / 2}\left[\frac{1}{a}\left(\frac{\tau_{1 / 2}}{\beta+1}\right)\left(b-V_{0}\right)\right]^{\frac{1}{\beta}}$

The areas under the TBM distributions and the calculated values of $S R\left(\tau_{1 / 2}\right)$ were plotted together with sunspot numbers in a same time scale to facilitate comparisons. In order to quantify the period and amplitude of seasonal oscillations of these data, they were fitted by the function $f(T)$ defined by the Equation 3, in which $T$ is the time in years. The year 1980 was considered as the zero on the time scale.

The Equation 3 defines $f(T)$ as being the sum of a third order polynomial (necessary to fit the secular trend) and a sinusoidal term in which the parameters $P_{5}, P_{6}$ and $P_{7}$ are the amplitude, period in years and initial phase respectively.

$f(T)=P_{1}+P_{2} \cdot T+P_{3} \cdot T^{2}+P_{4} \cdot T^{3}+P_{5} \cdot \sin \left(\frac{2 \pi T}{P_{6}}+P_{7}\right)$

\section{RESULTS}

The TBM distributions were fitted to yearly suicide rates by age from 1980 to 2010 (Figure 1). The obtained parameter values with standard errors, chi-squares, degrees of freedom and p-values are shown in the Table 1. Despite the distributions fitted better the female data, even for males, the differences between fitting curves and statistical data were not significant (all $\mathrm{p}>0.05$ ), with the worst fit observed for the year $1987(\mathrm{p}=0.975)$.

We organized the curves for the male datasets in a 3D graph in order to depict their annual evolution over the studied period (Figure 2). By performing numerical integrations, we determined the areas under the fitted distributions for males and females. Such areas are shown in the Figure 3a with the sunspot numbers for solar cycles 21, 22 and 23 on the same time scale. In the same way, the calculated middleage suicide rates $S R\left(\tau_{1 / 2}\right)$ are shown together with sunspot data in Figure 3B.

As previously explained, the values of $S R\left(\tau_{1 / 2}\right)$ and the areas under the TBM distributions were fitted by the 

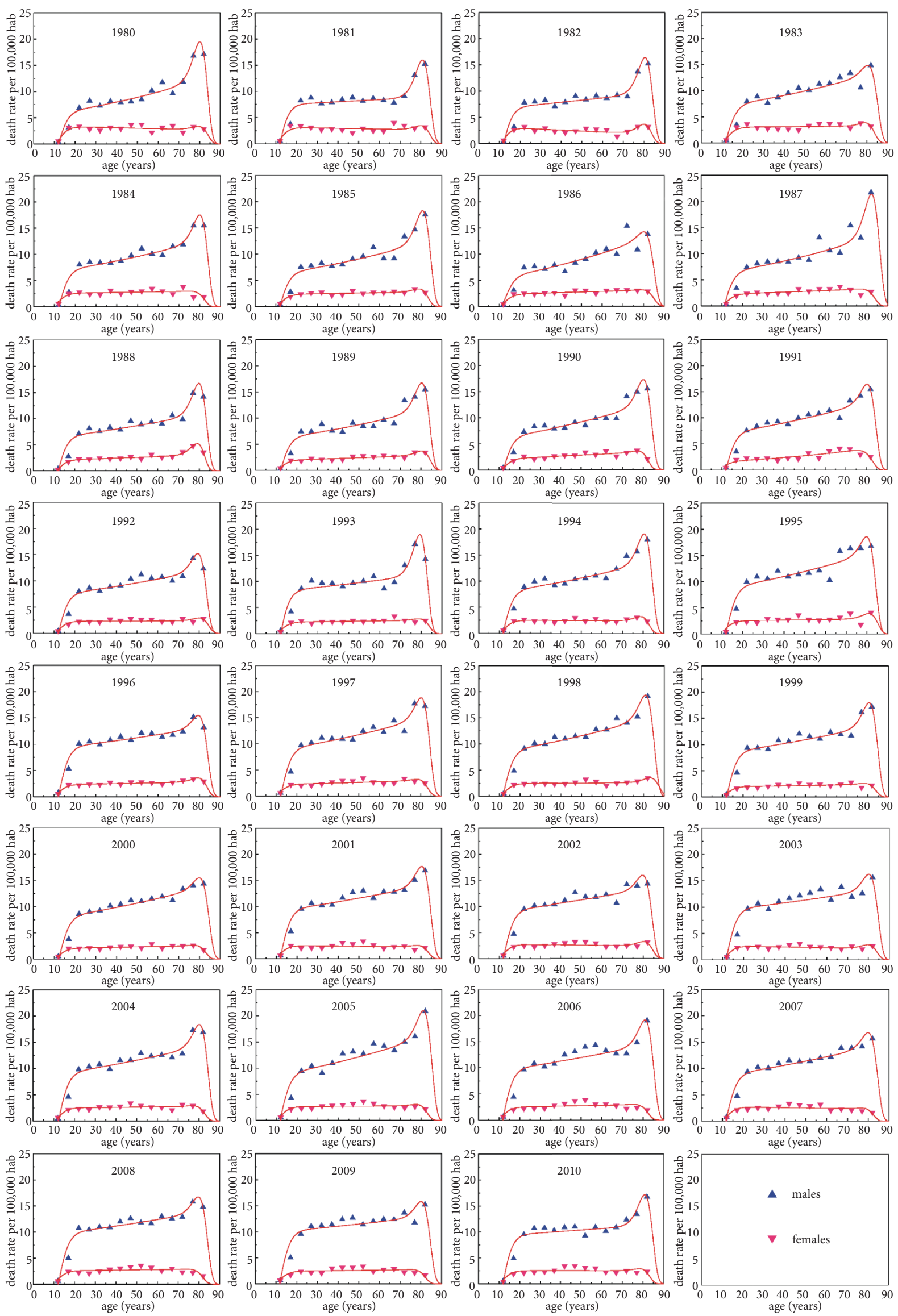

Figure 1. Annual suicide rates by age and gender in Brazil from 1980 to 2010 . The continuous curves shown in red are the Threshold Bias Model (TBM) distributions fitted to each statistical dataset 
Table 1. Threshold Bias Model parameter values

\begin{tabular}{|c|c|c|c|c|c|c|c|c|c|}
\hline Year & Gender & $C_{a p}$ & $a$ & $b($ year -1$)$ & $\tau_{1 / 2}($ year $)$ & $V_{0}($ year -1$)$ & $\chi^{2}$ & $d f$ & $\mathrm{p}$-value \\
\hline \multirow[t]{2}{*}{1980} & M & $77.0(9.1)$ & $12.8(1.4)$ & $0.120(0.014)$ & 45 & $0.0108(0.0020)$ & 1.498 & 10 & 0.998 \\
\hline & $\mathrm{F}$ & $17.4(9.3)$ & $14.3(6.2)$ & $0.172(0.099)$ & $45.5(2.0)$ & $-0.0030(0.0033)$ & 1.104 & 10 & 0.999 \\
\hline \multirow[t]{2}{*}{1981} & M & $90.9(9.3)$ & $10.4(1.3)$ & $0.092(0.011)$ & 45 & $0.0026(0.0018)$ & 1.287 & 10 & 0.999 \\
\hline & $\mathrm{F}$ & $19.2(10)$ & $11.7(5.1)$ & $0.149(0.085)$ & $45.3(2.1)$ & $-0.0027(0.0039)$ & 1.476 & 10 & 0.999 \\
\hline \multirow[t]{2}{*}{1982} & M & $82.9(9.3)$ & $11.3(1.4)$ & $0.102(0.012)$ & 45 & $0.0051(0.0019)$ & 1.589 & 10 & 0.998 \\
\hline & $\mathrm{F}$ & $30.8(7.8)$ & $7.6(2.0)$ & $0.073(0.024)$ & $44.1(0.8)$ & $-0.0073(0.0033)$ & 0.827 & 10 & 0.999 \\
\hline \multirow[t]{2}{*}{1983} & M & $47.8(10.4)$ & $17.7(5.1)$ & $0.211(0.045)$ & 46.5 & $0.0089(0.0024)$ & 2.249 & 11 & 0.997 \\
\hline & $\mathrm{F}$ & $17.4(7.8)$ & $13.5(5.2)$ & $0.181(0.086)$ & $45.2(1.4)$ & $0.0010(0.0030)$ & 0.889 & 10 & 0.999 \\
\hline \multirow[t]{2}{*}{1984} & M & $67.5(8.3)$ & $16.0(2.1)$ & $0.145(0.018)$ & 45.5 & $0.0091(0.0019)$ & 1.808 & 10 & 0.997 \\
\hline & $\mathrm{F}$ & $7.9(4.2)$ & $16.7(5.2)$ & $0.352(0.19)$ & 45 & $0.0022(0.0036)$ & 1.374 & 11 & 0.999 \\
\hline \multirow[t]{2}{*}{1985} & M & $72.1(10.4)$ & $13.2(2.5)$ & $0.130(0.019)$ & 45.5 & $0.0100(0.0023)$ & 2.133 & 10 & 0.995 \\
\hline & $\mathrm{F}$ & $14.5(3.4)$ & $13.8(3.0)$ & $0.176(0.044)$ & $45.0(0.7)$ & $0.0026(0.0018)$ & 0.231 & 10 & 0.999 \\
\hline \multirow[t]{2}{*}{1986} & M & $37.8(11.2)$ & $19.0(7.2)$ & $0.240(0.068)$ & 46.5 & $0.0124(0.0031)$ & 2.979 & 11 & 0.991 \\
\hline & $\mathrm{F}$ & $9.5(2.3)$ & $17.7(4.0)$ & $0.290(0.070)$ & 46.5 & $0.0038(0.0019)$ & 0.405 & 11 & 0.999 \\
\hline \multirow[t]{2}{*}{1987} & M & $88.6(19.5)$ & $8.6(3.5)$ & $0.113(0.024)$ & 45.5 & $0.0104(0.0032)$ & 3.799 & 11 & 0.975 \\
\hline & $\mathrm{F}$ & $7.8(3.4)$ & $18.8(5.9)$ & $0.36(0.15)$ & 46 & $0.0053(0.0031)$ & 0.947 & 11 & 0.999 \\
\hline \multirow[t]{2}{*}{1988} & M & $72.1(8.9)$ & $13.4(1.6)$ & $0.123(0.015)$ & 45 & $0.0078(0.0020)$ & 1.722 & 10 & 0.998 \\
\hline & $\mathrm{F}$ & $25.7(3.0)$ & $10.2(1.6)$ & $0.105(0.013)$ & $43.99(0.34)$ & $0.0057(0.0017)$ & 0.186 & 10 & 0.999 \\
\hline \multirow[t]{2}{*}{1989} & M & $66.1(9.4)$ & $14.7(2.4)$ & $0.136(0.019)$ & 45.5 & $0.0094(0.0023)$ & 1.825 & 10 & 0.998 \\
\hline & $\mathrm{F}$ & $15.4(3.6)$ & $11.5(2.9)$ & $0.159(0.039)$ & $45.3(0.98)$ & $0.0058(0.0021)$ & 0.308 & 10 & 0.999 \\
\hline \multirow[t]{2}{*}{1990} & M & $63.7(8.4)$ & $15.4(2.2)$ & $0.147(0.019)$ & 45.5 & $0.0104(0.0020)$ & 1.483 & 10 & 0.999 \\
\hline & $\mathrm{F}$ & $10.7(2.4)$ & $20.4(3.1)$ & $0.259(0.057)$ & 45.3 & $0.0067(0.0021)$ & 0.427 & 11 & 0.999 \\
\hline \multirow[t]{2}{*}{1991} & M & $59.0(7.2)$ & $17.2(2.6)$ & $0.171(0.021)$ & 46 & $0.0091(0.0017)$ & 1.294 & 10 & 0.999 \\
\hline & $\mathrm{F}$ & $5.4(5.2)$ & $12.7(6.5)$ & $0.49(0.46)$ & 45 & $0.0135(0.0038)$ & 1.307 & 11 & 0.999 \\
\hline \multirow[t]{2}{*}{1992} & M & $58.3(7.3)$ & $18.0(2.1)$ & $0.167(0.021)$ & 45.5 & $0.0071(0.0018)$ & 1.381 & 10 & 0.999 \\
\hline & $\mathrm{F}$ & $13.8(2.6)$ & $12.7(2.6)$ & $0.169(0.034)$ & 45.5 & $0.0005(0.0022)$ & 0.431 & 11 & 0.999 \\
\hline \multirow[t]{2}{*}{1993} & M & $94.4(11)$ & $12.2(1.1)$ & $0.106(0.013)$ & 44.5 & $0.0049(0.0020)$ & 1.757 & 10 & 0.998 \\
\hline & $\mathrm{F}$ & $10.8(2.7)$ & $14.5(3.4)$ & $0.222(0.058)$ & 45.5 & $0.0022(0.0025)$ & 0.637 & 11 & 0.999 \\
\hline \multirow[t]{2}{*}{1994} & M & $78.8(8.4)$ & $13.5(1.8)$ & $0.138(0.015)$ & 45.5 & $0.0078(0.0016)$ & 1.339 & 11 & 0.999 \\
\hline & $\mathrm{F}$ & $16.9(2.4)$ & $11.9(1.4)$ & $0.145(0.022)$ & 44.5 & $-0.0004(0.0019)$ & 0.336 & 11 & 0.999 \\
\hline \multirow[t]{2}{*}{1995} & M & $65.4(10.8)$ & $18.8(3.6)$ & $0.185(0.030)$ & 46 & $0.0083(0.0022)$ & 2.229 & 10 & 0.994 \\
\hline & $\mathrm{F}$ & $19.8(7.5)$ & $7.8(4.1)$ & $0.137(0.055)$ & 45 & $0.0020(0.0045)$ & 2.058 & 11 & 0.998 \\
\hline \multirow[t]{2}{*}{1996} & M & $58.4(5.8)$ & $20.1(2.1)$ & $0.194(0.019)$ & 46 & $0.0052(0.0012)$ & 0.802 & 10 & 0.999 \\
\hline & $\mathrm{F}$ & $15.9(2.7)$ & $11.7(2.0)$ & $0.163(0.029)$ & $44.83(0.53)$ & $0.0031(0.0014)$ & 0.149 & 10 & 0.999 \\
\hline \multirow[t]{2}{*}{1997} & M & $70.8(8.5)$ & $18.2(2.6)$ & $0.169(0.020)$ & 46 & $0.0077(0.0017)$ & 1.418 & 10 & 0.999 \\
\hline & $\mathrm{F}$ & $11.1(3.3)$ & $13.5(3.1)$ & $0.236(0.069)$ & 45 & $0.0041(0.0027)$ & 0.693 & 11 & 0.999 \\
\hline \multirow[t]{2}{*}{1998} & M & $74.6(8.6)$ & $14.5(2.3)$ & $0.159(0.018)$ & 46 & $0.0081(0.0015)$ & 1.226 & 11 & 0.999 \\
\hline & $\mathrm{F}$ & $18.7(5.3)$ & $9.9(3.3)$ & $0.138(0.041)$ & 46.66 & $0.0012(0.0012)$ & 0.334 & 11 & 0.999 \\
\hline 1999 & M & $73.4(8.0)$ & $16.0(2.3)$ & $0.152(0.017)$ & 46 & $0.0068(0.0015)$ & 1.192 & 10 & 0.999 \\
\hline & $\mathrm{F}$ & $8.9(2.6)$ & $14.8(3.8)$ & $0.249(0.074)$ & 45.5 & $0.0032(0.0027)$ & 0.596 & 11 & 0.999 \\
\hline 2000 & M & $51.1(6.0)$ & $22.0(3.2)$ & $0.211(0.025)$ & 46.5 & $0.0080(0.0014)$ & 1.108 & 10 & 0.999 \\
\hline & $\mathrm{F}$ & $8.3(1.9)$ & $17.4(2.8)$ & $0.279(0.063)$ & 45.35 & $0.0031(0.0019)$ & 0.324 & 11 & 0.999 \\
\hline 2001 & M & $70.7(7.7)$ & $16.2(2.2)$ & $0.166(0.018)$ & 46 & $0.0061(0.0039)$ & 1.409 & 11 & 0.999 \\
\hline & $\mathrm{F}$ & $10.9(4.5)$ & $12.3(4.2)$ & $0.219(0.095)$ & 45 & $-0.0015(0.0039)$ & 1.414 & 11 & 0.999 \\
\hline 2002 & M & $60.4(8.3)$ & $18.8(2.9)$ & $0.187(0.026)$ & 46 & $0.0057(0.0017)$ & 2.745 & 11 & 0.994 \\
\hline & $\mathrm{F}$ & $18.6(4.1)$ & $9.8(2.4)$ & $0.136(0.033)$ & 45 & $-0.0021(0.0027)$ & 0.754 & 11 & 0.999 \\
\hline 2003 & M & $65.7(11.6)$ & $16.3(3.5)$ & $0.175(0.031)$ & 46 & $0.0049(0.0022)$ & 2.381 & 11 & 0.997 \\
\hline & $\mathrm{F}$ & $16.4(3.4)$ & $10.9(2.3)$ & $0.144(0.033)$ & 45 & $-0.0030(0.0026)$ & 0.640 & 11 & 0.999 \\
\hline 2004 & M & $72.4(7.9)$ & $18.1(2.4)$ & $0.163(0.018)$ & 46 & $0.0069(0.0015)$ & 1.291 & 10 & 0.999 \\
\hline & $\mathrm{F}$ & $9.6(2.6)$ & $18.1(3.4)$ & $0.276(0.074)$ & 45.33 & $0.0016(0.0023)$ & 0.522 & 11 & 0.999 \\
\hline
\end{tabular}


Table 1. Continuation

\begin{tabular}{lccccccccc} 
Year & Gender & $C_{a p}$ & $\boldsymbol{a}$ & $\boldsymbol{b}($ year -1$)$ & $\tau_{1 / 2}$ (year) & $V_{0}($ year -1$)$ & $\chi^{2}$ & $d f$ & p-value \\
2005 & $\mathrm{M}$ & $80.4(12)$ & $14.2(3.1)$ & $0.155(0.023)$ & 46 & $0.0086(0.0020)$ & 2.300 & 11 & 0.997 \\
& $\mathrm{~F}$ & $11.7(3.4)$ & $15.3(3.3)$ & $0.233(0.069)$ & 45 & $0.0007(0.0028)$ & 0.814 & 11 & 0.999 \\
2006 & $\mathrm{M}$ & $81.3(13.5)$ & $14.4(3.3)$ & $0.149(0.025)$ & 46 & $0.0059(0.0022)$ & 2.840 & 11 & 0.993 \\
& $\mathrm{~F}$ & $8.3(4.5)$ & $16.7(5.4)$ & $0.327(0.176)$ & 45 & $0.0024(0.0039)$ & 1.507 & 11 & 0.999 \\
2007 & $\mathrm{M}$ & $61.0(7.2)$ & $17.2(2.4)$ & $0.189(0.022)$ & 46 & $0.0070(0.0014)$ & 1.170 & 11 & 0.999 \\
& $\mathrm{~F}$ & $9.8(3.6)$ & $16.7(4.3)$ & $0.256(0.098)$ & 45 & $-0.0024(0.0033)$ & 1.062 & 11 & 0.999 \\
2008 & $\mathrm{M}$ & $65.3(6.9)$ & $19.4(2.3)$ & $0.182(0.020)$ & 46 & $0.0053(0.0014)$ & 1.154 & 10 & 0.999 \\
& $\mathrm{~F}$ & $7.4(3.6)$ & $18.5(5.0)$ & $0.369(0.180)$ & 45 & $0.0017(0.0033)$ & 1.113 & 11 & 0.999 \\
2009 & $\mathrm{M}$ & $66.4(11.1)$ & $16.5(3.3)$ & $0.174(0.030)$ & 46 & $0.0037(0.0021)$ & 2.142 & 11 & 0.998 \\
& $\mathrm{~F}$ & $7.8(3.7)$ & $17.7(5.0)$ & $0.33(0.16)$ & 45 & $0.0018(0.0035)$ & 1.141 & 11 & 0.999 \\
2010 & $\mathrm{M}$ & $89.6(10.5)$ & $12.2(1.8)$ & $0.117(0.015)$ & 45.5 & $0.0027(0.0017)$ & 2.102 & 11 & 0.998 \\
& $\mathrm{~F}$ & $12.7(4.4)$ & $13.8(4.0)$ & $0.200(0.073)$ & 45 & $-0.0001(0.0037)$ & 1.352 & 11 & 0.999 \\
\hline
\end{tabular}

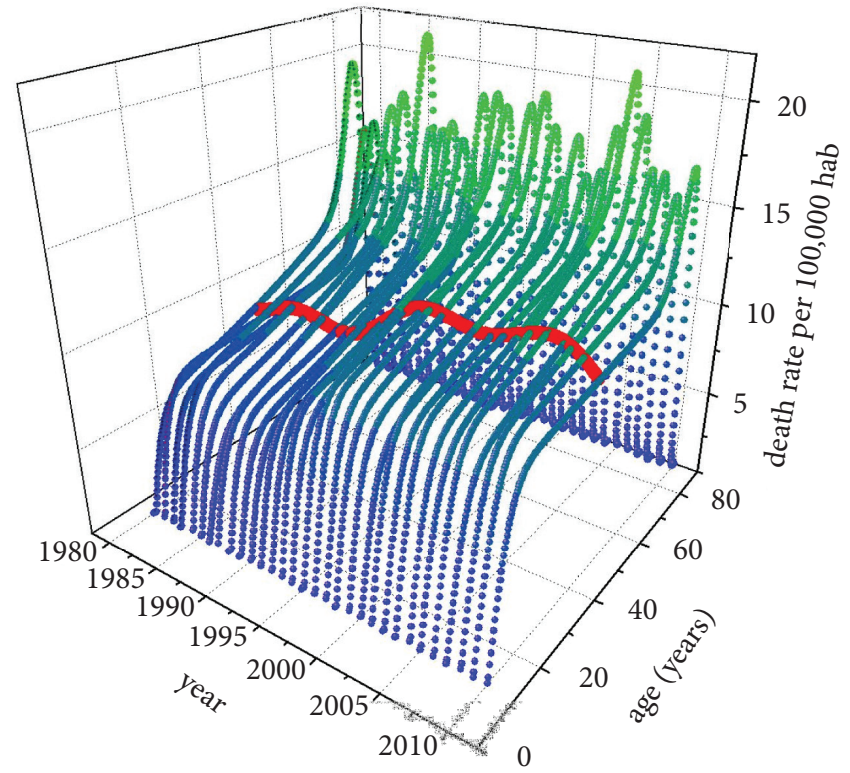

Figure 2. 3D representation of male Threshold Bias Model distributions plotted as functions of age and year. The continuous curve shown in red represents the annual evolution of middle-age death rates by suicide

function $f(T)$ defined by the Equation 3. The obtained parameter values with respective standard errors, chi-squares, degrees of freedom and p-values are shown in Table 2. It was observed that the amplitude (modulus of parameter $P_{5}$ shown in Table 2) of the sinusoidal part of $f(T)$ fitted to $S R\left(\tau_{1 / 2}\right)$ is about $6 \%$ of the average value of this quantity for males and $3 \%$ for females. In addition, it was found that the periods of the sinusoidal part of $f(T)$ (values in years of $P_{6}$ shown in Table 2) are closely compatible with the 11-year sunspot cycles. The Figures $3 \mathrm{a}$ and $\mathrm{b}$ show that the areas under the TBM distributions and the values of $S R\left(\tau_{1 / 2}\right)$ present three events of minima in the studied time range: the first in 1979-1980, the second in 1989-1990 and the third in 2001-2002. Such events occurred at approximately the same years of maxima of the sunspot cycles 21,22 and 23 (Figures $3 \mathrm{~A}$ and $\mathrm{B}$ ).

\section{DISCUSSION}

Albeit some researchers have reported positive correlations between suicide rates and sunspot numbers ${ }^{4}$, our preliminary results are in agreement with the findings of several other authors who have reported negative correlations between these phenomena ${ }^{5-7}$.

Since the middle-age suicide rates $S R\left(\tau_{1 / 2}\right)$ and the areas under the TBM distributions are relatively immune to data fluctuations over the studied age groups, the results of present research can be considered as relatively robust.

Despite the observed oscillations in suicide rates be more prominent for males, they were also noticeable for females. For males, these oscillations are observed over all age groups, but become more intense with increasing ages (Figure 2). Such a progression with age was not clearly observed in the female rates. In Brazil, due to occupational factors, men are more likely to be exposed to sunlight than women ${ }^{14}$. This fact may hypothetically explain the greater amplitude of oscillations observed in the male suicide rates although this hypothesis has not been tested in the present study. The reader should also be aware that the present results (obtained from nationwide population data) might not be valid at regional level. Interpretations of such results as being valid for small cohorts can lead to ecological fallacy ${ }^{15}$.

The neurobiological mechanism linking suicide with solar activity remains unknown. Recent studies have positively correlated suicide occurrence with low levels of melatonin ${ }^{16}$ in populations exposed to increased number of sunlight hours. As such correlation was not investigated in the present work, further researches are required in order to clarify this point. 
Table 2. Parameter values of $f(T)$ obtained for $S R\left(\tau_{1 / 2}\right)$ and for integrated $S R(t)$

\begin{tabular}{|c|c|c|c|c|c|c|c|c|c|c|c|}
\hline$f(T)$ & G & $P_{1}$ & $P_{2}$ & $P_{3}$ & $P_{4}$ & $P_{5}$ & $P_{6}$ & $P_{7}$ & $x^{2}$ & $d f$ & p-value \\
\hline \multirow[t]{2}{*}{$\operatorname{SR}\left(\tau_{1 / 2}\right)$} & M & $8.67(0.35)$ & $-0.186(0.093)$ & $0.0296(0.0067)$ & $-0.00071(0.00014)$ & $-0.57(0.11)$ & 11.7 & $8.29(0.19)$ & 0.39 & 25 & 0.999 \\
\hline & $\mathrm{F}$ & $3.01(0.15)$ & $-0.072(0.039)$ & $0.0029(0.0028)$ & $-0.00003(0.00006)$ & $-0.072(0.044)$ & 11.7 & $1(0.63)$ & 0.25 & 25 & 999 \\
\hline \multirow[t]{2}{*}{$\begin{array}{l}\text { Integral } \\
\text { of } S R(t)\end{array}$} & M & 709.6 & 17 & $63)$ & $-0.048(0.013)$ & -35 & 10.8 & 1.17 & 34.2 & 23 & 0.062 \\
\hline & $\mathrm{F}$ & $217.2(11)$ & $-4.95(2.96)$ & $0.21(0.21)$ & $-0.0030(0.0044)$ & $4.61(3.25)$ & 10.8 & $-1.86(0.8)$ & 20.4 & 24 & 0.726 \\
\hline
\end{tabular}
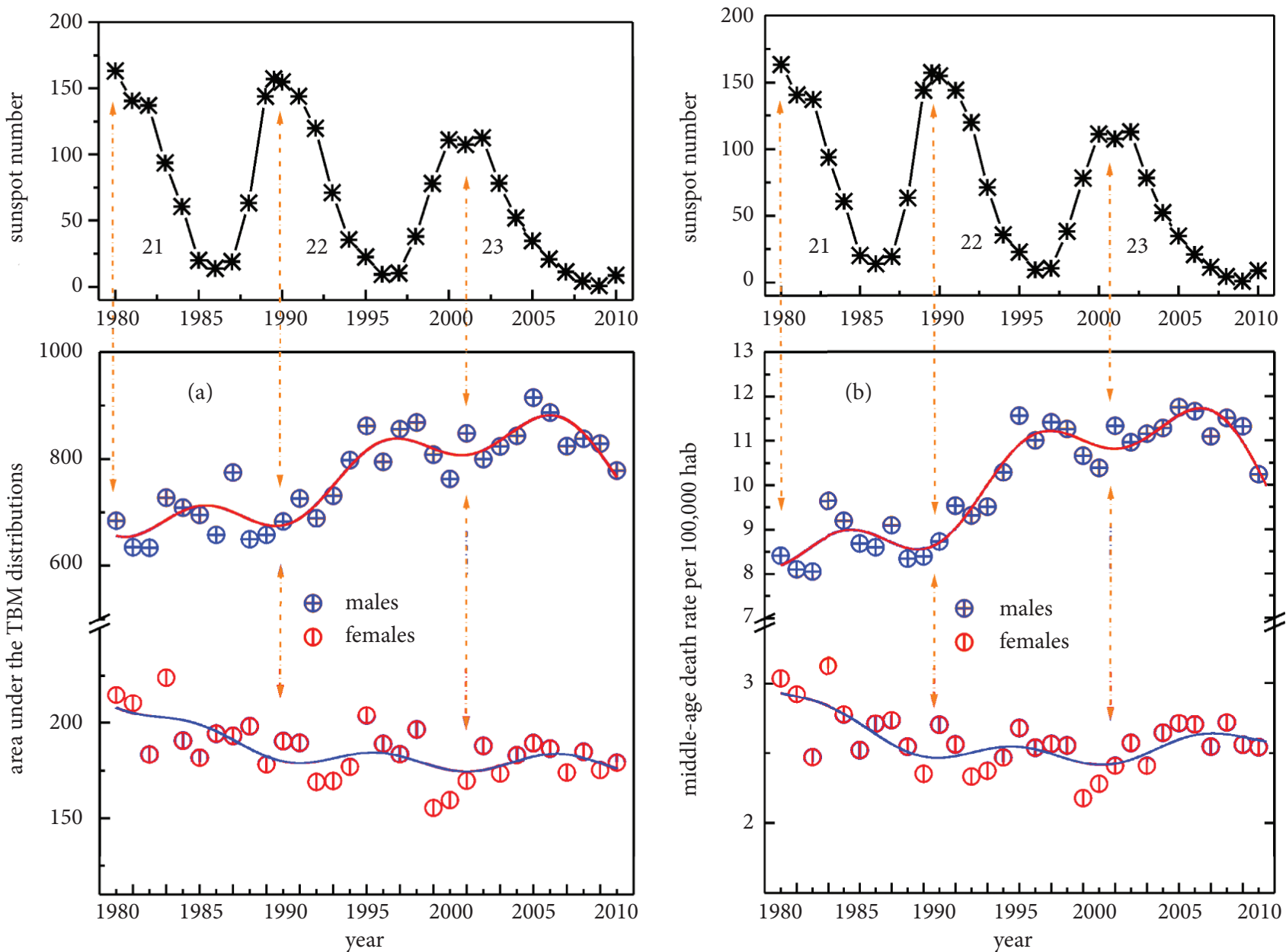

Figure 3. Sunspot numbers during solar cycles 21, 22 and 23 plotted together with (A) the areas under Threshold Bias Model (TBM) distributions and $(B)$ the middle-age death rates by suicide. The continuous curves shown in red and blue were obtained by fitting the function defined by the Equation 3 to these data for males and females respectively

\section{REFERENCES}

1. Lambert G, Reid C, Kaye D, Jennings G, Esler M. Increased suicide rate in the middle-aged and its association with hours of sunlight. Am J Psychiatry. 2003;160(4):793-5.

2. Björkstén KS, Kripke DF, Bjerregaard P. Accentuation of suicides but not homicides with rising latitudes of Greenland in the sunny months. BMC Psychiatry. 2009;9:20.

3. Nejar KA, Benseñor IM, Lotufo PA. Sunshine and suicide at the tropic of Capricorn, São Paulo, Brazil, 1996-2004. Rev Saude Publica. 2007;41(6):1062-64.

4. Dimitrov BD, Atanassova PA, Rachkova MI. Cyclicity of suicides may be modulates by internal or external 11-year cycles: An example of suicide rates in Finland. Sun and Geosphere. 2009;4(2):50-4.
5. Stoupel E, Abramson E, Sulkes J, Martfel J, Stein N, Handelman M, Shimshoni M, Zadka P, Gabbay U. Relationship between suicide and myocardial infarction with regard to changing physical environmental conditions. Int J Biometeorol. 1995;38(4):199-203.

6. Túnyi I, Tesarová O. [Suicide and geomagnetic activity]. Soud Lek. 1991; 36(1-2):1-11.

7. Stoupel E, Petrauskiene J, Kalediene R, Abramson E, Sulkes J. Clinical cosmobiology: The Lithuanian study 1990-1992. Int J Biometeorol. 1995;38(4):204-8

8. Hakko H, Räsänen P, Tiihonen J, Nieminen P. Use of statistical techniques in studies of suicide seasonality, 1970 to 1997. Suicide Life Threat Behav. 2002;32(2):191-208. 
9. Nader IW, Pietschnig J, Niederkrotenthaler T, Kapusta ND, Sonneck G, Voracek M. Suicide seasonality: Complex demodulation as a novel approach in epidemiologic Analysis. PLOS ONE. 2011;6(2):e17413.

10. Folly WSD. The Threshold Bias Model: A mathematical model for the nomothetic approach of suicide. PLOS ONE. 2011;6(9):e24414.

11. DATASUS - Informações de saúde [database on the Internet]. Brasil: Ministério da Saúde. 2011 [cited 2012 May 7]. Available from: http://tabnet.datasus.gov.br/cgi/deftohtm.exe?sim/ cnv/obt10uf.def Portuguese.

12. SIDC - Solar Influences Data Analysis Center [Internet]. Brussels: Royal Observatory of Belgium. 2011 [cited 2012 May 2]. Available from: http:// sidc.be/sunspot-index-graphics/sidc_graphics.php
13. Microcal Origin [computer program]. Version 5.0. Northampton (MA): Microcal Software Inc.

14. Szklo AS, Almeida LM, Figueiredo V, Lozana VER, Mendonça GAS, Moura L, et al. Comportamento relativo à exposição e proteção solar na população de 15 anos ou mais de 15 capitais brasileiras e Distrito Federal, 2002-2003. Cad Saude Publica. 2007;23(4):823-34.

15. Robinson W S. Ecological correlations and the behavior of individuals. Am Sociol Ver. 1950;15(3):351-7.

16. Havaki-Kontaxaki BJ, Papalias E, Kontaxaki M-EV, Papadimitriou GN. Seasonality, suicidality and melatonin. Psychiatriki. 2010;21(4):324-31.

Received on: 04/10/2012 Accepted on: 07/01/2013 